\title{
Assessment of Barangay Nutrition Action Plan (BNAP) Implementation in Selected Municipalities in Ifugao, Bulacan and Siquijor: Barangay Nutrition Scholars' Perspectives
}

\author{
Ma. Socorro Endrina-Ignacio \\ Department of Nutrition, College of Public Health, University of the Philippines Manila
}

\begin{abstract}
Introduction. The Barangay Nutrition Action Plan (BNAP) is the local version of the Philippine Plan of Action for Nutrition (PPAN), the country's directional framework for nutrition improvement. The Barangay Nutrition Scholars (BNS) spearhead the BNAP implementation.
\end{abstract}

Objective. To assess the implementation of BNAP in selected municipalities with high and low prevalence of undernutrition in the province of Ifugao, Bulacan, and Siquijor.

Materials and Methods. Qualitative method of data collection was employed to assess the BNAP formulation and implementation. A total of 57 BNS consented to participate in a focus group discussion.

Results. This paper presents the BNS perspectives on how BNAP is formulated and implemented in their barangays. While program elements that distinguish the low and high prevalence municipalities were observed, unique program elements, which may explain the program impact in terms of children's nutritional status, cannot be isolated. BNS' perception of the program inputs that contributed to the positive outcome of the BNAP implementation are as follows: political support, functional barangay nutrition committees, support and guidance from their supervisors, and their high credibility in the community as source of nutrition information that serves as their inspiration and motivation. The perceived program processes that contributed to improving the nutritional status of children in the community, are as follows: the presence of inter-agency collaboration, collective formulation of the BNAP, BNS' resourcefulness and innovativeness in soliciting support from other BNC member agencies.

Discussion and Recommendations. Across all municipalities, the BNS shared similar program inputs and processes that they perceived can contribute to improved BNAP implementation. They shared similar recommendations ranging from increased

Corresponding author: Ma. Socorro E. Ignacio, RND, DrPH

Department of Nutrition

College of Public Health

University of the Philippines Manila

625 Pedro Gil St., Ermita, Manila 1000 Philippines

Telephone: +6325255858

Email: meignacio1@up.edu.ph budgetary support for nutrition activities, more incentives for BNS (both monetary and non-monetary), security of tenure as BNS and cooperation from the community beneficiaries in their barangays. In high prevalence municipalities, BNS hope that the NNC will take notice of their problems particularly those that relate to BNAP implementation. Majority hopes that their appointment be apolitical to ensure their security of tenure. Some proposed that their Barangay Chairs be oriented on BNAP, BNC, BNS and their important roles in BNAP implementation. Recommendations to improve BNAP implementation included: political support to ensure funding of BNAP, functional BNC, continuous guidance from their supervisors, continuous BNS capacity building to enhance their program management skills and to enable them to effectively promote inter-agency collaboration and sustained advocacy at the national level for the passage of the Magna Carta for BNS that will increase their allowance and provide them with opportunities to upgrade technical capability to efficiently plan and manage local nutrition programs.

Key Words: Philippine Plan of Action for Nutrition, Barangay Nutrition Action Plan, Barangay Nutrition Scholars, Barangay Nutrition Committee, localization of PPAN

\section{Introduction}

The Philippine Plan of Action for Nutrition (PPAN) is the country's blueprint for planning nutrition interventions at the local levels. Since 1974, the National Nutrition Council (NNC) has formulated eight (8) PPAN. ${ }^{1}$ These plans have been cascaded to the municipalities to direct the implementation of barangay nutrition programs for almost 40 years now. Unfortunately, the nutrition situation in the country has not improved significantly based on the National Nutrition Surveys conducted by the Food and Nutrition Research Institute (FNRI). As shown in Table 1, although the prevalence of underweight among 0-60 months decreased from $27.4 \%$ in 1990 to $20.2 \%$ in 2011, the annual average reduction of 0.34 percentage points for the past 21 years is not fast enough or way below to achieve one of the targets of the Millennium Development Goal 1 (MDG1) which is to halve the proportion of underweight children (from 27.4 percent in 1990 to 13.7 percent by 2015). . $3,4^{3}$

Hunger incidence in the country remains a serious concern. Official government statistics and data from hunger 
surveys show an increasing trend in hunger incidence among Filipino households. ${ }^{5}$ The National Statistical Coordination Board (NSCB) reported that the percentage of subsistence poor in the country increased to 14.6 percent in 2006 from 13.5 percent in $2003 .{ }^{6}$

Table 1. Trends in malnutrition prevalence among children 0-60 months based on WHO-CGS: Philippines, 1990-2011

\begin{tabular}{lcccc}
\hline Year & $\begin{array}{c}\text { Underweight } \\
\mathbf{( \% )}\end{array}$ & $\begin{array}{c}\text { Under height } \\
\mathbf{( \% )}\end{array}$ & $\begin{array}{c}\text { Wasting } \\
\mathbf{( \% )}\end{array}$ & $\begin{array}{c}\text { Overweight } \\
\text { for Height } \mathbf{( \% )}\end{array}$ \\
\hline 1990 & 27.4 & 44.7 & 6.2 & 1 \\
1993 & 26.6 & 38.9 & 7.7 & 1.5 \\
1996 & 23.6 & 39.9 & 6.2 & 1.6 \\
1998 & 25.5 & 38.9 & 6.8 & 1.4 \\
2001 & 23 & 35.9 & 6.8 & 2 \\
2003 & 20.7 & 33.8 & 6 & 2.4 \\
2005 & 20.2 & 33.1 & 5.8 & 2.5 \\
2008 & 20.7 & 32.4 & 6.9 & 3.3 \\
2011 & 20.2 & 33.6 & 7.3 & 4.3 \\
\hline
\end{tabular}

PPAN 2011-2016 is the country's $8^{\text {th }}$ national plan for nutrition. Its goals include the reduction of child and maternal mortality. The PPAN key strategies are a "mix of services that are specific to the form of malnutrition and those that would impact on all forms of undernutrition" ${ }^{1}$ PPAN serves as a guide in formulating the Municipal Nutrition Action Plan (MNAP). The BNAP strategies are anchored on the MNAP. $8,9,10$ These include the following: a) promotion of breastfeeding, b) provision of complementary feeding program for young children less than 5 years old, c) conduct of nutrition education/promotion, d) integration of nutrition services in ante-natal care, e) promotion of integrated package of nutrition services in the school, f) provision of micronutrient supplements to reduce the prevalence of vitamin A deficiency, iodine deficiency disorders and iron deficiency anemia among infants aged 611 months old, one-year -olds, pregnant and lactating women, g) promotion of backyard gardening and h) promoting healthy lifestyle to prevent overweight and obesity among children and adults.

Local government units (LGUs) plays a crucial role in implementing PPAN throughout the country through MNAP and BNAP implementation. The BNAP planning and implementation are facilitated by the Barangay Nutrition Committee (BNC). This committee replicates the interagency composition of the NNC to serve as the coordinating structure for nutrition action at the sub-national level. Under the directive of the Department of Interior and Local Government (DILG) the local chief executives (i.e. mayors and barangay chairpersons) are mandated to provide leadership in nutrition planning, implementation, monitoring and evaluation of nutrition programs at the local level. As mandated by law, they are expected to designate BNS, provide logistical support and oversee the implementation of nutrition programs at the barangay level. ${ }^{7}$
This commissioned maiden study was conducted to assess the extent of PPAN localization in selected barangays with varying undernutrition prevalence. It gathered nutrition program implementers (BNS) perspectives to come up with a more inclusive and comprehensive assessment of nutrition program implementation at the barangay level. The document will serve as a guide for the various local stakeholders in addressing the problem of malnutrition, poverty and inequity in their respective areas. Through this study, local nutrition planners will be guided by the expressed sentiments and perceptions of the BNS, on how to improve the program implementation at the barangay level.

\section{Objectives}

Overall, the study aimed to assess the implementation of BNAP in selected municipalities with high and low prevalence of undernutrition in Ifugao, Bulacan, and Siquijor. Specifically, it aimed to identify factors that influenced BNAP formulation and implementation in the selected barangays to address the malnutrition problems as perceived by the BNS using the input-output-outcome logic model.

\section{Materials and Methods}

\section{Study Design and Data Collection}

Qualitative methods with appreciative inquiry processes were employed to describe how nutrition programs are developed and implemented in the selected barangays in municipalities with high and low prevalence of undernutrition. BNS perspectives were explored to come up with a more inclusive and comprehensive assessment of BNAP planning and implementation processes. Fifty-seven (57) BNS consented to participate in the focus group discussion. Documents review was also done to understand the local implementation of the BNAP. Documents reviewed included the BNC organizational structure and composition, updated barangay nutrition action plans, annual BNAP implementation accomplishment reports, minutes of the BNC meetings, annual Operation "Timbang" (OPT) report submitted to the municipalities.

\section{Selection of Study Sites and Participants}

The selection of the three provinces for assessment was based on the severity and magnitude of underweight among 0-60 months children as revealed in the FNRI 2011 Updating Survey (3). In classifying the prevalence of undernutrition in the selected areas, the classification of the worldwide prevalence ranges based on WHO standard in 1995 was used. Prevalence of undernutrition is considered low if the rate is <10; medium if rate is between 10-19; high if rate is between 20-29 and very high if rate is $>=30$ (Table 2). From each province, two municipalities with the lowest and highest prevalence of underweight among 0-71 month-old 
Table 2. Basis for the selection of study barangays

\begin{tabular}{ll}
\hline Study Site & Basis for Selection \\
\hline $\begin{array}{l}\text { Province } \\
\text { - Low, medium, high prevalence of }\end{array}$ & WHO Classification \\
$\quad$ underweight 0-60 months based & Medium: 10-20 \\
on FNRI 2011 updating survey & High: 21-30 \\
& Very High: $>30$ \\
$\begin{array}{l}\text { Municipality } \\
\text { - High and low prevalence }\end{array}$ & Based on 2011 Operation Timbang \\
$\begin{array}{l}\text { Barangay } \\
\text { - High and low prevalence }\end{array}$ & Based on 2012 Operation Timbang \\
\hline
\end{tabular}

Table 4. MELLPI standing of the selected provinces

\begin{tabular}{|c|c|c|c|}
\hline Year & Ifugao & Bulacan & Siquijor \\
\hline 2009 & None & CROWN Year 1 & None \\
\hline 2010 & CROWN Year 1 & $\begin{array}{l}\text { CROWN First Year } \\
\text { Maintenance }\end{array}$ & None \\
\hline 2011 & $\begin{array}{l}\text { CROWN First Year } \\
\text { Maintenance }\end{array}$ & $\begin{array}{l}\text { CROWN Second } \\
\text { Year Maintenance }\end{array}$ & None \\
\hline 2012 & $\begin{array}{l}\text { Vying for CROWN Second } \\
\text { Year Maintenance }\end{array}$ & $\begin{array}{l}\text { Vying for Nutrition } \\
\text { Honor Award }\end{array}$ & None \\
\hline
\end{tabular}

Source: NNC MELLPI Report (unpublished)
Table 3. Prevalence of underweight (0-60 months) in the selected provinces

\begin{tabular}{lll}
\hline Province & Prevalence $^{1}$ & Classification $^{2}$ \\
\hline Ifugao & 7.2 & Low \\
Bulacan & 13.3 & Medium \\
Siquijor & 46.0 & Very high \\
National prevalence average & 20.2 & \\
Prevalence Range & $7.2-46$ & \\
\hline${ }^{1}$ Based on 2011 updating survey of FNRI & \\
${ }^{2}$ Based on WHO Classification &
\end{tabular}

Table 5. Prevalence of underweight children (0-71 months) in the selected municipalities

\begin{tabular}{llll}
\hline $\begin{array}{l}\text { Municipality } \\
\text { Classification }{ }^{1}\end{array}$ & Ifugao & Bulacan & Siquijor \\
\hline Low & Lagawe (2.96) & Sta. Maria (1.40) & E. Villanueva (2.13) \\
High & Kiangan (3.65) & DRT (8.63) & San Juan (8.46) \\
Average prevalence & 3.76 & 2.52 & 6.26 \\
Prevalence Range & $2.04-6.32$ & $0.06-8.63$ & $2.13-8.46$ \\
\hline${ }^{1}$ Based on 2012 OPT results (relative to other municipalities in the same province) \\
Note: Figures in parenthesis is the prevalence rate
\end{tabular}

Table 6. Prevalence of underweight children (0-71 months) in the selected barangays

\begin{tabular}{|c|c|c|c|c|c|}
\hline \multirow{2}{*}{ Province } & \multirow{2}{*}{ Municipality } & \multicolumn{2}{|c|}{ Barangay } & \multirow{2}{*}{ Prevalence Range } & \multirow{2}{*}{ Average Prevalence } \\
\hline & & Low & High & & \\
\hline \multirow{2}{*}{ Ifugao } & $\begin{array}{l}\text { Lagawe } \\
\text { (Low) }\end{array}$ & $\begin{array}{l}\text { Olilicon } \\
(0)\end{array}$ & $\begin{array}{l}\text { Boliwong } \\
\text { (3) }\end{array}$ & $0.0-12.5$ & 2.75 \\
\hline & $\begin{array}{l}\text { Kiangan } \\
\text { (High) }\end{array}$ & $\begin{array}{c}\text { Tuplac } \\
(2.75)\end{array}$ & $\begin{array}{c}\text { Baguinge } \\
(5.09)\end{array}$ & $0.0-7.34$ & 3.59 \\
\hline \multirow{2}{*}{ Bulacan } & $\begin{array}{l}\text { Sta. Maria } \\
\text { (low) }\end{array}$ & $\begin{array}{c}\text { Buenavista } \\
(.59)\end{array}$ & $\begin{array}{c}\text { Sta. Cruz } \\
(.83)\end{array}$ & $0.0-3.7$ & 1.13 \\
\hline & $\begin{array}{c}\text { DRT } \\
\text { (High) }\end{array}$ & $\begin{array}{c}\text { Camachile } \\
\text { (4.91) }\end{array}$ & $\begin{array}{c}\text { PulongSampaloc } \\
(5.74)\end{array}$ & Not available & Not available \\
\hline \multirow{2}{*}{ Siquijor } & $\begin{array}{l}\text { E. Villanueva } \\
\text { (Low) }\end{array}$ & $\begin{array}{l}\text { Libo } \\
(2.15)\end{array}$ & $\begin{array}{c}\text { Poblacion } \\
(4.54)\end{array}$ & $0.0-9.0$ & 3 \\
\hline & $\begin{array}{l}\text { San Juan } \\
\text { (High) }\end{array}$ & $\begin{array}{l}\text { Maite } \\
(6.49)\end{array}$ & $\begin{array}{c}\text { Cansayang } \\
(9.43)\end{array}$ & $1.37-12.7$ & 6.99 \\
\hline
\end{tabular}

${ }^{1}$ Based on 2012 OPT results (relative to other barangays in the same municipality)

Note: Figures in parenthesis is the prevalence rate

children based on the municipal OPT results for 2012 were selected. ${ }^{11,12,13}$ From each municipality, two barangays categorized as high prevalence and low prevalence based on the same 2012 OPT results were also selected (Table 5). Classification of high and low prevalence municipality/barangay is relative to the provincial and municipal ranking of the OPT results. In certain cases, when it is not recommended to go to the municipality/barangay with the highest and lowest ranking because of distance or security concerns, the next highest or lowest was selected. The Provincial Nutrition Action Officer (PNAO) and the MNAO were also consulted in the final selection of municipalities and barangays that were covered (Table 6). The BNS assigned in the barangays with low and high prevalence of malnutrition based on the latest OPT findings in their area (as a result of the secondary data documents review) and as confirmed by their MNAO were requested to participate in the FGD after securing their consent.

\section{Data processing and analysis}

Collected data were consolidated, summarized and analyzed. Themes arising from the focused group discussions were grouped and cross-checked with field notes and observations. Comparison and contrasts of the variables of the assessment framework (input-processoutcome) between and among provinces, municipalities and barangays using the prevalence of underweight as the unit of analysis was made.

\section{Limitation}

Given the limited coverage of this study, the aim was to simply describe rather than explain the phenomenon of 
interest. At best it could only serve as case studies which can be the basis for designing large scale assessment of PPAN implementation at the barangay level. Field realities, such as lack of an appropriate venue to conduct the FGD may have affected the responses of the respondents. This report was based mainly on the reported experiences and perceptions of the BNS respondents and on the records (i.e. accomplishment reports and previous year's BNAP) made available to the researcher.

\section{Results}

\section{Profile of Study sites}

The study was conducted in three provinces - Ifugao, Bulacan and Siquijor. The prevalence of underweight children (0-60 months old) in Ifugao was estimated to be $7.2 \%$ in the year 2011, which was the lowest among the Philippine provinces, while Siquijor had the highest prevalence of $46.0 \%{ }^{4}$ Prevalence rate of Bulacan for the same year is $13.3 \%$. (Table 3 ) In addition, Ifugao was selected to represent a community with indigenous people (IP).

From 2009 to 2011, Bulacan has been awarded the Consistent Regional Outstanding Winner (CROWN) as judged by the National Nutrition Council's Monitoring \& Evaluation for Local Level Planning and Implementation (MELLPI). ${ }^{14}$ The CROWN award is given to a municipality, city or province that has been adjudged by the interagency regional evaluation team as outstanding in the region in the implementation of its nutrition action plan for three consecutive years. ${ }^{14}$ For 2012, Bulacan vied for the Nutrition Honor Award (NHA). The NHA is given to CROWN awardees that have consistently shown outstanding performance in efforts for nutrition improvement for three consecutive years. They have been monitored by the regional and national nutrition evaluation teams for three years. Ifugao on the other hand received its first CROWN award in 2010, was able to maintain it in 2011 and vied for 2012, for its 2nd year maintenance CROWN award while Siquijor never won any award ${ }^{15}$ (Table 4).

The prevalence of underweight children (0-60 months old) of the municipalities and barangays selected for the study is shown in Tables 5 and 6 .

\section{Implementation of the BNAP at the local level}

\section{Delivery of nutrition services to the barangays}

The implementation of the BNAP is largely anchored on the approved MNAP. According to the BNS their MNAOs usually present the MNAP to the barangay officials during the meeting of the Association of the Barangay Chairs $(\mathrm{ABC})$. The MNAP information brought to the barangay is only activity based, i.e. regular weighing of preschool children, livelihood training, feeding programs, etc. After the MNAOs orientation of the local chief executives, the BNS take over in coordinating with their other officers of the barangay as well the Barangay Nutrition Committee (BNC) members, the planning and implementation of priority nutrition interventions based on the MNAP. This process was reported by both low and high prevalence municipalities. The same process is followed by the frontline agencies whose programs for the barangay include targeting the undernourished families. If the $\mathrm{BNC}$ is functional (meaning they have regular meetings), the BNS usually uses that opportunity to inform the members of priority nutrition activities for the year.

In some areas, where the President of the $A B C$ is a member of the BNC he/she gives the orientation on the approved MNAP during the ABC meeting. The BNS shared that MNAP discussion is part of the BNC meeting agenda. The Barangay Chair, who is also the BNC Chair shares the priority activities contained in the MNAP to the committee to be prioritized for the year. To what extent the member agencies would also consider the priority MNAP activities as priority of their respective organization cannot be ascertained by the respondents. In case of death of the head of the BNC or change in leadership (i.e. after local election), the MNAOs with assistance from the BNS re-orients the newly elected barangay officials about the BNC, its role in BNAP implementation, BNAP priority activities, BNS assigned in the barangays as well as the expectations from the local chief executives. More often than not, the BNS requests the MNAO to do the orientation to the newly elected officials. This is necessary so there is continuity of programs despite the change in administration, laments the respondents. The BNS are responsible for reaching out to the community beneficiaries to participate in various nutrition programs planned for the year. They are assisted by the BHWs and Mother Leaders in delivering nutrition services at the household level.

\section{BNS Perspectives on Target Clients Participation in Nutrition Activities}

The BNS encountered several difficulties in implementing the BNAP activities. These include the following: attitude of the target beneficiaries, commitment of the organic frontline agency workers to deliver their nutrition component and the physical characteristics of the barangay such as proximity, terrain and access to transportation. The passive attitude of some of the target beneficiaries is perceived as the major setback in delivering the nutrition services. According to the BNS, only few families of undernourished children will go out of their way to get the milk supplements intended for their children. More often than not, it is the BNS or Mother Leader who delivers the milk supplements to the houses of undernourished children. When probed why they think the families are passive, work and distance to the barangay hall are often cited as the reasons. For example, most of the 
families with undernourished children live far from the barangay hall where occasional feeding, milk distribution and mothers' classes are usually conducted. To reach the barangay hall, the families will have to spend for transportation which drains the already meager family resources.

\section{BNS Perspective on the different BNAP Components Membership of BNC}

As per PPAN implementation mechanism, the smallest unit (i.e., barangay level) is expected to effectively plan and manage the nutrition program at the community level. The participation of all stakeholders (GOs, NGOs and private groups) is expected. Multi-sectoral participation at the barangay level is operationalized through the Barangay Nutrition Committee (BNC). Further, it is stated that the BNC should as much as possible mirror the composition of the nutrition committee at the national, provincial and municipal levels. In the study barangays, whether low or high prevalence, the BNC differ in size and composition but it is always chaired by the Barangay Captain and the Vice Chair is either the wife of the Barangay Captain or the Kagawad on Health. The BNS is always a member of the BNC. Other members depend on what agencies are situated in the barangay and these are usually the midwife, school teacher, BHWs, Kagawad for Health and Sangguniang Kabataan. Some NGOs present in the barangay are also invited to become part of the BNC but only few have been mobilized to become members of the BNC as reported by the BNS. Having a BNC listed on paper is different from having a functional BNC.

In this study, functionality of BNC is defined according to the following parameters: 1) BNC is meeting regularly (with minutes approved by the BNC Chair), 2) BNC member agencies are involved in the following activities: a) BNAP formulation, b) BNAP implementation (with resource allocation) and, c) BNAP management (e.g. participates in monitoring BNAP progress in his agency and submits periodically status of accomplishment to the BNC Chair). As perceived by the BNS and gleaned from their responses, it can be said that the barangays in Bulacan (medium prevalence province) has functional BNC. This is noted both in low (Sta. Maria) and high (DRT) prevalence municipalities. On the other hand, the BNC in Ifugao (low prevalence province) are not very active as perceived by the BNS especially during the BNAP formulation. The committee is also not that involved in BNAP implementation. Hence, it can be said that the BNC is not functional. In high prevalence province (Siquijor), majority of the BNS said they have not organized the BNC in their respective barangays. Some of the BNS who continue to formulate BNAP annually using the existing form from the $\mathrm{MNAO}$, narrated that they get discouraged because when they showed the plans to their Barangay Captains they usually are given cold shoulders and informed that there is no budget for nutrition. When asked what is needed to have an active BNC, the BNS were in agreement that the stewardship of an active BNC depends on the leadership of the BNC Chair and the persistence of the BNS in convening a BNC meeting regularly.

\section{BNS Perceived Difficulties in Formulating and Implementing the BNAP}

The BNS, when asked if they encountered difficulties in formulating and implementing the BNAP, identified budgetary support to BNAP implementation and uncooperative BNC members were cited as major difficulties across the study areas (Table 7). The seriousness of this problem varies. In low and medium prevalence provinces, this is a concern but the BNS are able to implement some of the proposed activities in the BNAP with support from the Barangay Captain even with minimal support from the BNC (Ifugao). Some BNS reported that some BNC member agencies (mostly NGOs) were able to implement complementary projects i.e. feeding and livelihood activities to cover the gaps (Bulacan).

Table 7. Difficulties encountered by the BNS in BNAP Formulation

\begin{tabular}{lll}
\hline $\begin{array}{c}\text { Low Prevalence Municipalities } \\
\text { (Lagawe, Sta. Maria, E. Villanueva) }\end{array}$ & \multicolumn{1}{c}{$\begin{array}{c}\text { High Prevalence Municipalities } \\
\text { (Kiangan)* }\end{array}$} \\
\hline - $\quad \begin{array}{l}\text { No regular budget allocated } \\
\text { for nutrition programs }\end{array}$ & $\bullet$ & $\begin{array}{l}\text { No regular budget allocated } \\
\text { for nutrition programs }\end{array}$ \\
Uncooperative BNC & Uncooperative BNC \\
members/BNC difficult to & & $\begin{array}{l}\text { members/BNC difficult to } \\
\text { convene } \\
\text { convene }\end{array}$ \\
& $-\quad \begin{array}{l}\text { Looking for individual BNC } \\
\text { members to sign the BNAP }\end{array}$ \\
& \\
\end{tabular}

* San Juan does not have BNAP.

The BNAP is usually prepared by the BNS if his/her $\mathrm{BNC}$ is not active. The BNS lamented that although they facilitate the BNAP formulation, plans are usually not implemented due to lack of budget even if the plan contains activities that are applicable/doable in the barangay. Logistical problem is another major concern. The BNS even shoulder the cost of reproducing the forms. They also shared that even if they endorse the BNAP to the barangay council, the plan will not get any support because of alleged lack of budget. The BNS also shared that they need guidance on how to find financial support for their plans because the Barangay Captain have no budget allocation for nutrition. BNAP formulation and implementation is a big problem in one high prevalence municipality (San Juan, Siquijor). For the BNS, formulating BNAP is a useless exercise because of lack of support. Although some Barangay Captains give their full support to the BNS, others simply ignore them. One barangay has good support for nutrition because the Barangay Captain was a former BNS and she even increased 
the honorarium of the BNS. It is just unfortunate that the annual BNAP that they prepared is not funded due to different priorities of the barangay officials in the area. The BNS suggested that Barangay Captains should always be invited to attend meetings and seminars on nutrition so they would have an idea about the BNAP formulation.

\section{Participation of NGOs and private agencies in BNAP implementation}

The involvement of the NGOs and other private organizations in the implementation of the BNAP vary across municipalities. However, it can be concluded that the barangays from low and medium prevalence provinces (Ifugao and Bulacan) were able to mobilize more NGO involvement compared with the high prevalence province of Siquijor. In Sta. Maria and DRT in Bulacan, there were barangays where the NGOs actually implement projects (i.e. feeding, preschool education, and mothers' classes with livelihood component) to uplift the nutritional status of the children in the barangay. Other activities implemented by the NGOs in DRT include the following: mahogany seedlings distribution and water tank project to ensure supply of safe water in the barangay. One NGO which is also a member of BNC built a school house for day care children. In the same school, they also conduct feeding following the menu from DSWD. National Power Corporation is also a member of the BNC.

In Ifugao, the NGOs are very active as reported by the BNS. The following are the activities initiated and sustained by the NGOs: KIPHODAN, ASKI, CCF (Community Children's Fund), livelihood organization - sponsoring selected children and giving monthly allowance of P210, during December P500 and on June P850.

In Lagawe, BNS shared that the following NGOs contributed to the BNAP implementation: PCSO supported the establishment of a barangay health station and the Women's Organization President donated P1000 which was used to purchase medicines for the center.

On the other hand, some BNS in Siquijor had limited experience in getting support from NGOs. They narrated one partnership with the National Dairy but they had a problem with use of fresh milk in their feeding program. They requested for powdered milk but the organization was not able to support this request.

In E. Villanueva, Heartfelt, an NGO, supported the implementation of some of the activities in the BNAP. Before, USA provided some supplies for the feeding program. Other NGOs that provided support in their nutrition program requested to remain anonymous.

\section{Preparedness of BNS in BNAP formulation}

Majority of the BNS expressed confidence in formulating the BNAP because of the availability of coaches and mentors in the person of the senior BNS and MNAO
The BNS from Sta. Maria, Bulacan expressed that they do not need additional training on BNAP formulation and added that BNAP template is not that complicated to follow. Besides, the BNC usually helps them finalize the plan. They want more training on improving interpersonal skills and networking specifically, on dealing with different types of people so that they can generate more resources for BNAP implementation. The same sentiment was expressed from the BNS of DRT, Bulacan. They said that since the membership of the BNC is the same as in the previous years and have consistently been involved in BNAP formulation, they are guided on how to prepare the BNAP. They just change the target based on OPT findings and the set of activities are basically the same.

In Ifugao where majority of the BNS have reported to have been oriented on BNAP formulation and a few on PPAN, there were not much issue on BNAP formulation as some claimed to have been coached by the MNAO. Some have copies of the previous BNAP from the previous BNS that they use as reference. In Siquijor, the BNS from the low prevalence municipality (E. Villanueva), said their knowledge was just enough in formulating the BNAP. They were oriented by the nurse and former social development worker who became the MNAO. They have a pro-forma for BNAP development which they use. However, many expressed difficulty in using the format. There are BNS who shared that they did not have a hard time formulating their BNAP since there is an existing BNAP format that they follow but just the same they wanted to undergo formal training on BNAP formulation.

While majority of the BNS across all municipalities claim they do not need additional training in formulating the BNAP, analysis of the BNAP they prepared revealed variations in completeness and quality of entries. Upon review of previous $\mathrm{BNAP}$, that there were not many variations in the plan compared with the previous year's BNAP.

\section{Budget allocation and other concerns affecting BNAP implementation}

Budget is allocated for the implementation of the BNAP as reported by the BNS coming from either low or high prevalence municipality of Bulacan. The approved budgetary allocation for BNAP in said municipalities ranges from $\mathrm{PhP15,000} \mathrm{-} \mathrm{PhP80,000} \mathrm{with} \mathrm{built} \mathrm{in} \mathrm{allocation} \mathrm{for}$ allowances and honoraria of the BNS. As "barangay scholar", the BNS are supposed to receive a monthly allowance from their respective barangays as token of their services. These include: transportation and other expenses. The amount varies per barangay - from none to PhP 2,600 per month (Table 8). In Ifugao and Bulacan (low and medium prevalence provinces), the provincial and municipal government also augment the allowance of the BNS. The total allowance of the BNS in these provinces 
ranges from $\mathrm{PhP}$ 1,200 to 1,700. In Ifugao, while there is no separate budget for nutrition for each barangay, the BNS also received honorarium but the amount varies for each barangay which ranges from $\mathrm{PhP}$ 400-1, 100 per month. In addition, they also received from the municipality and from the province. The total amount that they received ranges from PhP 1,100 to $\mathrm{PhP} 2,600$ each month. This situation is contrary to what is experienced in the high prevalence province (Siquijor). The BNAP that they developed annually has no budgetary allocation. Neither honoraria nor allowance are given to BNS either from the barangay, municipal and provincial offices. Hence, the respondents have suggested that the Barangay Captains should attend seminar on nutrition, seminar for BNS and even this qualitative survey so they will appreciate the importance of nutrition. To improve self-rating of satisfaction in performing their role in BNAP implementation, BNS desires to receive more incentives, budget for BNAP, more support from the $\mathrm{BC}$, security of tenure and more cooperation from the community (Table 9). They also expressed specific "wish list" to improve BNAP implementation in their respective barangays (Table 10).

Table 8. BNS honorarium in the study areas

\begin{tabular}{lcccc}
\hline & $\begin{array}{c}\text { Barangay } \\
\mathbf{( P h P )}\end{array}$ & $\begin{array}{c}\text { Municipality } \\
\mathbf{( P h P )}\end{array}$ & $\begin{array}{c}\text { Province } \\
(\mathbf{P h P})\end{array}$ & $\begin{array}{c}\text { Total } \\
\mathbf{( P h P )}\end{array}$ \\
\hline Ifugao & $400-800$ & 500 & 200 & $1100-1700$ \\
Bulacan & $250-1100$ & 1000 & 500 & $1750-2600$ \\
Siquijor* & None & None & None & None \\
\hline
\end{tabular}

* BNS concurrently BHW; they are getting BHW incentive

Table 9. Suggestions on how to increase their level of satisfaction in their work

\begin{tabular}{lll}
\hline Suggestions & Municipality & Classification \\
\hline $\begin{array}{l}\text { Increased and additional incentives } \\
\text { (e.g. retirement fund, }\end{array}$ & $\begin{array}{l}\text { Lagawe, Ifugao } \\
\text { Keparation fund, PhilHealth) }\end{array}$ & $\begin{array}{l}\text { Low prevalence } \\
\text { Kigh prevalence }\end{array}$ \\
$\begin{array}{l}\text { Increased community } \\
\text { participation and cooperation }\end{array}$ & E. Villanueva, Siquior & Low prevalence \\
$\begin{array}{l}\text { Unity among health workers } \\
\text { and BNC }\end{array}$ & Kiangan, Ifugao & High prevalence \\
$\begin{array}{l}\text { Support from the local } \\
\text { and the national governments }\end{array}$ & San Juan, Siquijor & High prevalence \\
\hline
\end{tabular}

* No documented responses from Sta. Maria, Bulacan and DRT, Bulacan

\section{Perceived effects of nutrition program on beneficiaries/community}

The benefits of BNAP implementation is felt more in low prevalence province (Bulacan) both in high and low prevalence municipalities compared with high prevalence province both in low and high prevalence municipalities wherein respondents exhibited blank faces in citing what they think are the benefits of BNAP in people's lives in their respective barangays. BNS collectively shared that mothers enrolled in 4Ps in their barangays are more conscious of the nutritional status of their children compared to those who are non-4Ps beneficiaries. They thought that the benefits tied to the conditions are effective in influencing some of the health and nutrition behaviors of the 4Ps beneficiaries (Sta. Maria). Similar observations were raised by the respondents from high prevalence municipality (DRT). They added that 4Ps beneficiaries are more disciplined: they are aware or updated on the vaccination of their children and they monitor their children's weight, and committed to support the cleaning up their yards and their barangays as a whole. On the downside, they also expressed apprehension that the moment incentives are taken away, they think 4Ps beneficiaries will no longer be motivated to follow any health and nutrition advice.

In Ifugao, BNS claimed that as per their record, the number of malnourished children was reduced but there are still underweight children. They also noticed that other agencies are using their OPT data for planning and that they noticed that people are now participating in nutrition programs (Kiangan). Some BNS in Lagawe noticed the decrease in the number of pre-schoolers and they attribute this to their family planning program. People's level of nutrition awareness has increased as many are approaching them to clarify nutrition related concerns and validating if such is true. Increased cooperation in nutrition program was noted by the BNS in Lagawe. Table 11 summarizes the perceived effects of the nutrition activities to children's health.

\section{Recommendations/Suggestions to improve BNAP Implementation}

Across all municipalities, the BNS had similar recommendations ranging from increased budgetary support for nutrition activities, more incentives for BNS (both monetary and non-monetary), security of tenure as BNS and cooperation from the community beneficiaries in their barangays. In particular, the BNS from San Juan (high prevalence municipality) hopes that National Office (NNC) will take notice of their problem and the issues surrounding BNAP implementation. They hope that BNS appointment will be apolitical or not influenced by the change in barangay administration. They proposed that Barangay Captains be oriented on nutrition so they will appreciate the role of BNS in BNAP formulation and implementation. They are hoping that the Barangay chairpersons will be well informed about the importance of having a well funded BNAP. This way they will not have a difficult time convincing these local officials to support and provide funds for the BNAP as well as the organization /activation of BNC.

\section{Discussion and Recommendations}

Variations in the BNAP formulation and implementation in all various stages of program management in the covered areas were observed in this study. While program elements 
Table 10. Area- specific wish list to improve BNAP implementation

\begin{tabular}{|c|c|c|}
\hline Ifugao & Bulacan & Siquijor \\
\hline $\begin{array}{l}\text { - } \\
\text { baby bag not OBAN } \\
\text { - } \quad \text { Flashlight, umbrella, boots } \\
\text { - } \quad \text { Pravel \& food allowance } \\
\text { - } \quad \text { Retirement/separation package }\end{array}$ & $\begin{array}{ll}\text { - } & \text { Support for supplementary } \\
\text { feeding } \\
\text { - } & \text { Additional kits for teaching } \\
\text { mothers } \\
\text { - } \quad \text { Rice allowance, umbrella } \\
\text { - } \quad \text { Cooperative parent during OPT }\end{array}$ & $\begin{array}{l}\text { - } \quad \text { Support for feeding \& mother's classes } \\
\text { - } \quad \text { Seminar to community to reduce indifference and sarcastic } \\
\text { remarks to BNS } \\
\text { - } \quad \text { National Office (NNC) to look into their plight } \\
\text { - } \quad \begin{array}{l}\text { Orientation of Barangay Council on BNS role and importance } \\
\text { of organizing BNC and comprehensive BNAP }\end{array}\end{array}$ \\
\hline
\end{tabular}

Table 11. Observed positive effects of nutrition activities on children's health

\begin{tabular}{lll}
\hline Positive effects & Barangay & Classification \\
\hline Children gained weight & Buenavista, Sta. Maria & Low prevalence \\
& Libo, E. Villanueva & Low prevalence \\
& Tuplac, Kiangan & Low prevalence \\
& Camachile, DRT & Low prevalence \\
& Boliwong, Lagawe & High prevalence \\
& Sta. Cruz, Sta. Maria & High prevalence \\
& PulongSampalok, DRT & High prevalence \\
& Cansayang, San Juan & High prevalence \\
Weight improved but & Buenavista, Sta. Maria & Low prevalence \\
still underweight & & \\
Children learned to eat & Libo, E. Villanueva & Low prevalence \\
Vegetables and a variety & Tuplac, Kiangan & Low prevalence \\
& Camachile, DRT & Low prevalence \\
& Maite, San Juan & Low prevalence \\
& Boliwong, Lagawe & High prevalence \\
& Baguinge, Kiangan & High prevalence \\
& Cansayang, San Juan & High prevalence \\
& Olilicon, Lagawe & Low prevalence \\
& Libo, E. Villanueva & Low prevalence \\
& Tuplac, Kiangan & Low prevalence \\
Children's appetite improved & Maite, San Juan & Low prevalence \\
& Boliwong, Lagawe & High prevalence \\
& Sta. Cruz, Sta. Maria & High prevalence \\
& PulongSampalok, DRT & High prevalence \\
& Cansayang, San Juan & High prevalence \\
\hline
\end{tabular}

that distinguish the low and high prevalence municipalities were observed, unique program elements which may explain the program impact in terms of nutritional status of the preschool children cannot be isolated. The inputs and processes considered critical in program management are similarly found in both low and high prevalence provinces and municipalities.

An input considered crucial in the effective implementation of PPAN is political support. All national directives related to the PPAN localization are addressed to the local chief executive with the expectation that these directives are carried out well. One directive is the appointment of a Barangay Nutrition Scholar (BNS) and the organization of Barangay Nutrition Committee (BNC). The leadership and support of the local government can be seen in the organizational set-up and structure of the BNC and the functionality of the BNC. In this study, one cannot conclude that barangay organizational set-up made a difference because in general, both low and high prevalence municipalities share certain common characteristics such as the BNC is headed by the Barangay Chair and the BNAP implementation has no separate budget line item in the overall barangay budget.

Budget allocation is an indicator of political support. All BNS expressed that the nutrition program has inadequate budget. As reported and validated in the documents review, most municipalities do not have a separate Nutrition Office with a separate budget, funding support for the various intervention programs in the MNAP at the barangay level is limited to the available budget of the various line agencies expected to implement specific interventions as members of the BNC. Thus, other requirements of the nutrition program such as training of BNS, purchase of IEC materials, honorarium of the BNS are being sourced from various sources. BNS shared that their MNAOs usually request for supplemental budget from the Office of the Mayor - which renders some degree of uncertainty in terms of program sustainability. Funding support largely depend on the political climate and priorities of the incumbent local chief executive. While the BNS are appreciative of the cooperation of the different local agencies, the priority of the BNC member agencies were still their priority projects. Again, funding of nutrition related activities may not be sustained given this system.

The need for upgrading of BNS current capability surfaced in this study. All the BNS shared a perception that they were not technically prepared to perform the tasks expected of a BNS. They do not have formal orientation upon assumption of office. Many of them learned program management skills as they performed their functions. Most of the trainings that they received as BNS are all program/intervention specific. What differentiates the BNS from the low and high prevalence municipalities is the length of time they have been with the nutrition program.

Despite the concept of devolution, the BNS perceive the need for national directives to give them legal basis for their actions. They consider the DILG memorandum circular reiterating the LGU role in nutrition implementation very helpful. For them, a strong provincial, regional and national presence of the nutrition program at the local level may strengthen the local nutrition program. This hierarchical dependence for support from higher authorities may be both positive and negative for the nutrition program. Positive because it gives them negotiating tools with the local 
government to support the nutrition program but it may also discourage local initiatives. Although local nutrition initiatives are recognized in the Monitoring and Evaluation of Local Level Program Implementation (MELLPI) at the provincial, regional and national level, the impact programs that emanated from the top are given more points. Respondents clamor to have a uniform PPAN form for writing local accomplishment needs rethinking because implementers at the local level seem "boxed" in addressing their nutritional problems. Most of the local initiatives that they shared are just creative ways of implementing the impact programs prescribed in the PPAN. Real creativity and innovativeness of local implementers in addressing the nutrition problems within the context of their local situation need to be encouraged and supported. This way, their sense of ownership for the local nutrition program and empowerment of the local implementers is further enhanced.

Efficient reporting system is an important component of program management but the utility of reports depends on the accuracy and timeliness of the data. Collecting the needed information, consolidation and preparing the reports take up a considerable time of the BNS. Perhaps, the frequency of reporting and the usefulness of the reports the MNAOs required from the BNS to submit to the municipality need to be revisited as these might result to limited time spent on other aspects of program implementation. Further, the BNS expressed the need for regular session on report preparation and simple data analysis. They would like to be able to interpret the report to the BNC Chair and to the committee during their meetings so they can generate support to their programs.

The BNS recognize the importance of nutrition education in improving the nutrition behavior of the families. Given the limited funds for the nutrition program, sound nutrition advice is the only thing they can offer to the families. For them, nutrition advice does not entail additional cost to the program. Adoption of their nutrition advice by community beneficiaries are evident when they observed that it is being practiced by the caregivers during their home visitation. A cursory inventory of the available nutrition education materials found in the municipalities reveal that the low prevalence municipalities have more nutrition education materials compared to the high prevalence municipalities. Many of the low prevalence barangays also have a nutrition corner in their respective barangay hall where educational materials in nutrition are available. Thus, investments to develop and improve the communication and counselling skills of the BNS could be a cost-effective intervention. Investments can be in the form of training programs and acquisition of nutrition education materials. The need to strengthen the nutrition education component of the nutrition program was already recognized and strongly recommended in an earlier study done on the PPAN (Florencio, 1998).
Hindrances in BNAP implementation can be overcome if only there will be strong political will to support the BNAP and strong inter-agency collaboration that will expand the coverage and beneficiaries of barangay nutrition activities. The Chair of the BNC should be capacitated on how to maximize use of PPAN as guide in directing the support from partner agencies to ensure that nutrition projects will complement and supplement the limited activities that are supported by the Barangay Council.

The inputs that contributed to the positive outcome of the local level implementation of the PPAN are as follows: political support (with budget for nutrition), functional nutrition committees, MNAO's dedication and support to BNS, and dedicated BNS who despite BNAP's budgetary constraints and poor political support, enjoy high credibility and people's confidence in the community.

Whereas, the processes that contributed to the positive outcome of the local level implementation of PPAN are: presence of inter-agency collaboration, collective formulation of BNAP, and, resourcefulness and innovativeness in addressing issues and concerns related to nutrition implementation. The study surfaced the following areas of concern to improve the local level implementation of the PPAN. These concerns are as follows: political support, continuing capacity building, inter-agency collaboration and advocacy for the passage of the Magna Carta for BNS that will increase their allowance and provide them with opportunities to upgrade technical capability to efficiently plan and manage local nutrition programs. This bill seeks to uplift the morale of the BNS by providing security of tenure regardless of political affiliation and other benefits not provided in PD 1569. In the bill, a BNS after undergoing training shall serve for three years in the barangay with a yearly evaluation after which he/she will be given a permanent position after two years of continuous satisfactory rating. The BNS can also avail of second grade civil service eligibility by filling proper application and meeting the requirements. Other benefits include P2,000 monthly allowance, monthly hazard pay of P120, a uniform allowance, enrolment to Phil health and a scholarship grant (if deserving) to any institution offering two years' course.

\section{References}

1. National Nutrition Council. Philippine Plan of Action for Nutrition, Abridged version. NNC Secretariat, April 13, 2013. Unpublished.

2. Food and Nutrition Research Institute. Philippine Nutrition Facts and Figures 2005. FNRI-DOST, 2007. pp.14-15.

3. Food and Nutrition Research Institute. Philippine Nutrition Facts and Figures 2011. FNRI-DOST, 2012 Table 2.1. pp. 3-5.

4. Food and Nutrition Research Institute. Philippine Nutrition Facts and Figures 2011. FNRI-DOST, 2012. pp.48-49.

5. National Economic and Development Authority. "Status Report on the Millennium Development Goals Using CBMS Data" [Online]. 2010 [cited 2012 June]. Available from http:// www.neda.gov.ph/econreports_ dbs/MDGs/4thProgress2010/PROVINCIAl_Reports/Siquijor/pdf. 
6. National Statistics Office. The 2010 Census of Population and Housing Reveals the Philippine Population at 92.34 Million" [Online]. 2012 [cited 2012 June]. Available from http://www.census.gov.ph/content/2010-censuspopulation-and-housing-reveals-philippine-population-9234-million.

7. Department of Interior and Local Government Memorandum Circular No.2012-89[Online]. 2011 [cited 2012 July]. Available from www.dilg.gov.ph.

8. Annual Accomplishment Reports 2010,2011, 2012, Ifugao (MNAO file). Unpublished.

9. Annual Accomplishment Reports 2010, 2011,2012, Bulacan (MNAO file). Unpublished.
10. Annual Accomplishment Reports 2010,2011,2012, Siquijor (PNAO file). Unpublished.

11. OPT Report, Ifugao,2012 (BNS file). Unpublished.

12. OPT Report, Bulacan,2012 (BNS file). Unpublished.

13. OPT Report, Siquijor, 2012 (BNS file). Unpublished.

14. National Nutrition Council. Guidelines on the Monitoring and Evaluation of Implementation of the Philippine Plan of Action for Nutrition at Provincial, City and Municipalities. NNC Secretariat, 2006.

15. National Nutrition Council. Awarding Ceremony Program. Philippine International Convention Center, November 9, 2012.

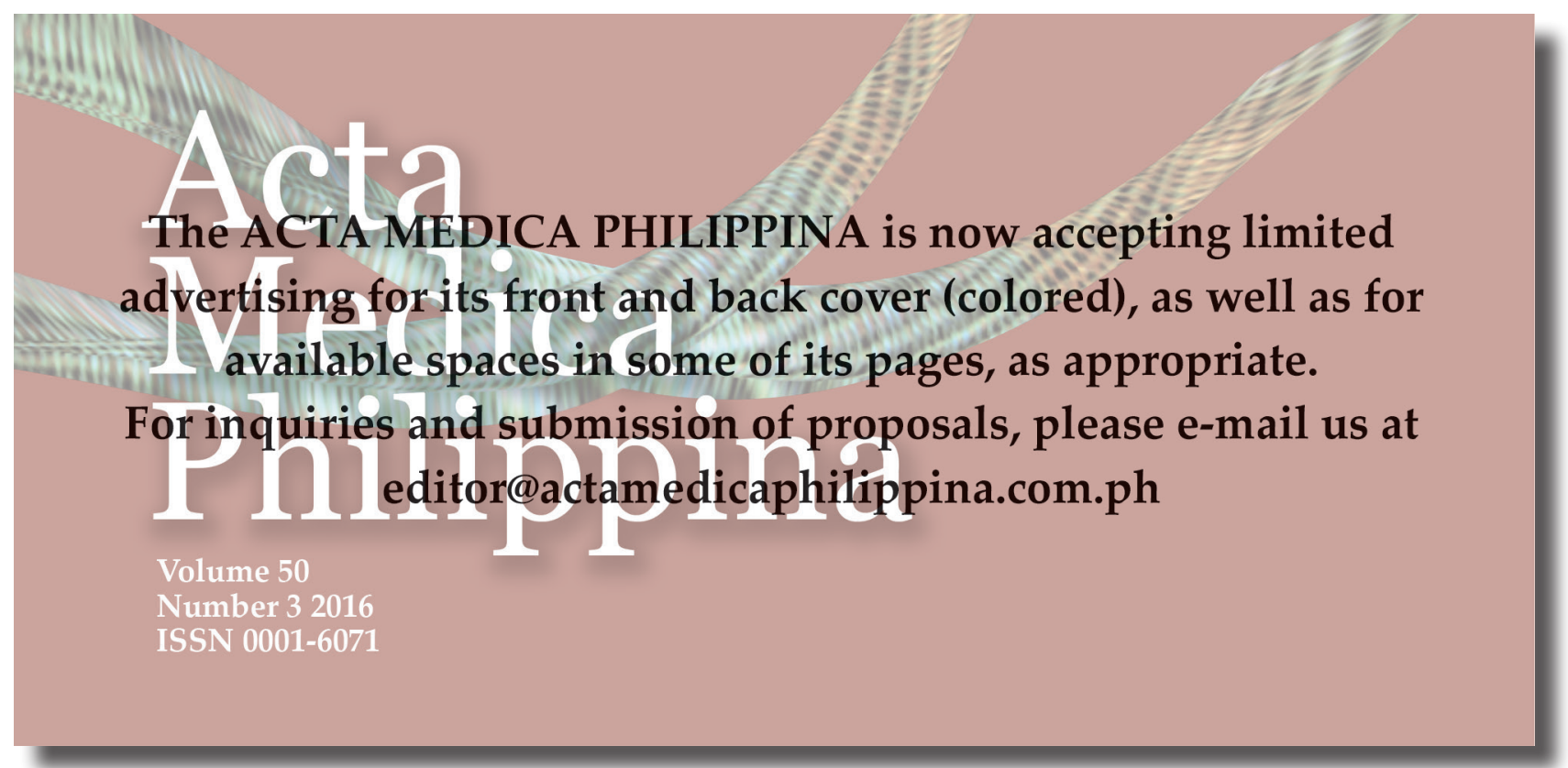

